\title{
Comovement and FTSE 100 Index Changes*
}

\author{
JERRY COAKLEY and PERIKLIS KOUGOULIS \\ Department of Accounting, Finance and Management, University of Essex
}

This version: April 2004

\begin{abstract}
We employ the Barberis, Shleifer and Wurgler (2004) methodology to investigate the impact of changes to the FTSE 100 index on return comovement over the 1992-2002 period. For FTSE stock inclusions the average increase in the beta coefficient is 0.38 in univariate regressions for weekly returns and 0.60 in bivariate regressions that control for the return on non-FTSE stocks. Stocks deleted from the index display the opposite pattern post exit. The results are robust to a number of factors including size, industry and non-trading effects. They are difficult to explain within a classical framework but complement those found for the US and Japan in supporting behavioral views of comovement.
\end{abstract}

JEL classification: G11, G12, G14

Keywords: Behavioral finance; trading-based comovement, index funds.

*We thank Ana-Maria Fuertes, Eric Girardin, Terry Mills, Giorgio Valente, to participants at the Anglo-French Macroeconomics and Finance Workshop, University College Oxford, April 2004 and at seminars at the Universities of Essex and Loughborough for helpful comments. Kougoulis is grateful for financial support provided by the Greek State Scholarship Foundation (IKY). Corresponding author: Jerry Coakley, Department of Accounting, Finance and Management, University of Essex, Wivenhoe Park, Cochester C04 3SQ. Tel +44 1206 872455. Fax +44 1206 873429. E-mail: jcoakley@essex.ac.uk 


\section{Introduction}

The analysis of the impact of changes in the constituent firms of stock market indices has garnered growing interest in recent years. A stock's inclusion in or deletion from an equity index is of interest for two reasons. On one hand it is an event based on publicly available information. On the other, it is arguable whether such changes in the index have any direct impact on a stock's fundamentals. If its inclusion in the index has a value to a particular firm, then this can only be by way of a change in the demand for its stock. In particular, if index inclusion (deletion) leads to an increase (decrease) in demand, then the nature of the price effects observed around index changes can shed light on the specific determinants of the price effects.

The price effect of stock index changes has been the subject of debate for a number of years. One interesting finding is that $\mathrm{S} \& \mathrm{P}$ index inclusion is associated with a permanent increase in stock price which has been interpreted as meaning that demand curves for stocks slope downwards. For instance Harris and Gurel (1986), Shleifer (1986), and Lynch and Mendenhall (1997) establish significant price effects for S\&P 500 inclusions. More recently, Wurgler and Zhuravskaya (2002) support this view by providing evidence that demand curves for stocks slope downwards which implies limits to arbitrage. ${ }^{1}$ Similar effects have been found for other stock exchanges: Kaul, Mehrotra and Morck (2000) for the Toronto Stock Exchange TSE 300 and Greenwood (2001) for the Nikkei 225 index on the Tokyo Stock Exchange.

Another aspect of index redefinition that has been studied is return comovement around events such as entry to and exit from a stock market index. In a pioneering study, Vijh (1994) examined some 329 stocks added to the S\&P 500 index during the 1975-1989 period. He shows that stock betas with respect to the market are overstated and vice versa for non-index stock betas due to liquidity price effects caused by index-trading strategies. While the effects are relatively minor during the 1975-1984 period, they are more marked in the 1985-1989 period. For instance, daily and weekly betas of stock additions during the latter period increase by 0.211 and 0.130 , respectively, on average. The difference between monthly betas of otherwise similar S\&P 500 and non-S\&P 500 stocks is 0.125 during the same period.

Vijh argues some of these increases stem from the reduced non-sychronous

\footnotetext{
${ }^{1}$ More recently Chen, Noronha and Singal (2004) posit an asymmetric price response to index changes stemming from changes in investor awareness.
} 
nature of S\&P 500 stock price changes but that the remaining increases are explained by the price pressure or excess volatility caused by the S\&P 500 trading strategies. He estimates that the price pressures account for 8.5 percent of the total variance of daily returns of a value-weighted portfolio of NYSE/AMEX stocks. Vijh's study is related to that of Harris (1989) who also addresses the excess-volatility implications of S\&P 500 trading. He concludes that trading in S\&P 500 index futures and options increases cash index volatility measured over various short term windows 1982-1987.

The Vijh study has been both updated and extended in an important recent behavioral finance contribution by Barberis, Shleifer and Wurgler (2004). ${ }^{2}$ This extends the earlier comovement studies at both the theoretical and empirical levels. At a theoretical level they distinguish between traditional or fundamentals-based approaches and market friction- or investor sentiment-based approaches to comovement and develop models of the latter. The fundamentals-based view asserts that changes in comovement stem from correlated changes in cash flows or common variation in discount factors. By contrast, the other approaches stress behavioral factors such as investor sentiment or market frictions such as limits to arbitrage.

Barberis et al. (2004) distinguish among three variants of the behavioral or trading-based approach. One is the category view developed by Barberis and Shleifer (2003) that argues that investors group stocks into categories such as a market index prior to asset allocation. Another is the (preferred) habitat view that is based on the presumption that investors trade just a subset of available securities such as small cap stocks. Finally, the information diffusion view posits that information is incorporated more rapidly in some stocks rather than in others due to the influence of market frictions in the latter case. The basic idea in that in each of these three views, the existence of correlated investor sentiment and/or market frictions leads to discernible trading patterns in particular groups of securities such as those comprising a market index. In the later case, such influences will manifest themselves as changes in return comovement leading to a change in a stock's beta coefficient with the index.

Barberis et al. (2004) update Vijh (1994) by studying the impact of these entry and exit events for the S\&P 500 index for the 1976-2000 period. They extend his methodology by considering the results from bivariate as well as univariate regressions and by conducting a number of robustness checks.

\footnotetext{
${ }^{2}$ See Barberis, Shleifer and Wurgler (2002) for an earlier version.
} 
They find in univariate regressions that when a stock is added to the index, its beta and coefficient of determination with respect to the index increase by an average of 0.11 and 0.033 , respectively, for weekly returns. The converse happens when a stock is deleted. Changes are more pronounced for the most recent period 1988-2001 consistent with an increase in the popularity of index funds and trading in index-related products such as derivatives.

One of their major findings is that the beta changes are even larger when they consider bivariate regressions that control for the return of non-S\&P stocks. The betas increase by an average of 0.202 while simultaneously their betas with respect to non-index stocks fall by an average of -0.115 for weekly returns 1988-2001. Because inclusion in the S\&P 500 index conveys no news about fundamentals, this evidence is hard to reconcile with the fundamentals view of comovement but is supportive of behavioral views. ${ }^{3}$

Greenwood and Sosner (2002) also test the Barberis et al. model using a recent one-time major change in the Nikkei 225 index. In April 2000, 30 new stocks were added to and 30 others deleted from the Nikkei. They find evidence of significant increases in beta and $R^{2}$ following a stock's addition to the index and of decreases following deletions. ${ }^{4}$ For instance the daily betas of 28 added stocks rose by an average of 0.60 while those for 30 deleted stock fell by an average of $0.71 .^{5}$

This paper makes two contributions to the comovement literature First, it tests the comovement hypotheses for changes to the FTSE 100 index of London Stock Exchange which is the world's leading stock exchange outside New York both in terms of market capitalization and of turnover. In this respect it complements the study of Barberis et al. (2004) for the S\&P 500 and that of Greenwood and Sosner (2002) for the Nikkei 225 index. Changes in the composition of the FTSE 100 Index are based purely on the relative market capitalization of the actual and potential constituent firms. For this reason, the size effect takes on particular importance in our study and we evaluate this in our robustness tests.

The FTSE 100 index was introduced in the London Stock Exchange in 1984 prior to Big Bang or the raft of liberalization reforms implemented

\footnotetext{
${ }^{3}$ See Denis et al. (2003) the view that index entry signifies an increase in expected future earnings.

${ }^{4}$ Kaul, Mehrotra, and Morck (2000) find similar effects in the Toronto Stock Exchange TSE 300 .

${ }^{5}$ The topic of index changes is also of interest to practitioners as the literature on the recent MSCI index changes indicates. See Commerzbank (2002).
} 
shortly thereafter. In 1992 a set of changes was introduced governing the procedures for entry to and exit from the index to accommodate the introduction of stock index futures and stock options on LIFFE. Thus we study the impact of these changes on the beta coefficients and $R^{2}$ of stock involved in these changes for the 1992-2002 period. By contrast the Greenwood and Sosner study focuses on a one-time, large event related to a redefinition of the Nikkei index in 2000.

Second, our findings provide strong evidence of the influence of behavioral or trading-based factors on stock price returns. As such it adds to the growing body of evidence that fundamental factors cannot explain all aspects of stock return comovement. In this respect it complements recent studies that underline the importance of behavioral factors in explaining changes in financial economics. Our results offer even more striking evidence in favor of the friction- and sentiment-based views of comovement than those of Barberis et al. (2004). The changes, both for inclusions and deletions, are strongly significant and thus provide additional support for the behavioral theories of comovement. For instance, the increase in weekly beta coefficients for additions to the FTSE is 0.603 in bivariate regressions which control for non-FTSE returns 1992-2002. This increase is some 0.74 for the 1998-2002 period.

The paper is organized as follows. In Section 2 we outline the traditional and behavioral finance models of comovement and summarize the predictions of the latter models. Sections 3 and 4 discuss the empirical results. A final section concludes.

\section{Theories of Comovement}

Theories of comovement can be classified into two broad groups as Barberis et al. (2004) suggest. One is the traditional fundamentals-based framework of frictionless economies with fully rational investors while the other comprises behavioral approaches. The latter approaches are distinct in being tradingbased approaches in which noise traders, market sentiment or frictions play a significant role. ${ }^{6}$

\footnotetext{
${ }^{6}$ See Barberis, Shleifer and Vishny (1998), Daniel, Hirshleifer and Subrahmanyam (1998) and Hong and Stein (1999) on the role of these factors in models of stock returns.
} 


\subsection{Traditional versus Behavioral Models}

In the fundamentals-based framework, comovement in fundamental values is immediately reflected in comovement in prices. Changes may stem from revised expectations about future cash flows and/or shocks to the appropriate discount rates. Thus comovement in prices and returns can be explained by comovement in news about fundamental factors. Such changes will in turn lead to correlated changes in stock betas. There is agreement that the fundamentals view of comovement explains many instances of common factors in stock returns. Dotcom stocks move together because there is a common component to news about their future earnings.

Behavioral approaches to comovement relax the frictionless market and fully rational investor assumptions. Barberis et al. (2004) distinguish between three such approaches. The first is the category view that builds on the recent Barberis and Shleifer (2003) model of style investment. The latter refers to the different categories of assets or investment styles that investors follow such as index funds, small cap stocks, value stocks, dotcom stocks, bonds and so on. The intuition behind style investment is that investors engage in asset allocation rather than individual stock picking when making their portfolio decisions. Thus they decide on the relative merits of categories of assets and then allocate funds at this level rather than at the individual security level.

The implication of style investing is that, in the case of a style such as index funds, investors will trade when the companies included in the index change rather than on the basis of changes in fundamentals in such companies. As such, these investors' behavior is similar to that of noise traders with correlated sentiment. Thus if their trading affects prices, their coordinated demand will induce common factors in the returns of assets that happen to be in the index even if these assets' cash flows are largely uncorrelated.

The preferred habitat view originates from the bond markets and is based on the notion that investors choose to invest in a restricted class of assets only. It is based on the observation that many investors select preferred habitats for their trades. This could be explained by factors such as transaction costs or international trading restrictions. For instance, Lee, Shleifer, and Thaler (1991) argue that closed-end mutual funds are a preferred habitat of individual investors. As a result their market prices comove with such investors' demand shifts although their fundamentals do not comove with these same shifts. As investors' sentiment changes, they alter their exposure 
to their preferred habitat. It is the latter which induces a common factor in the returns of the securities that comprise the habitat. More generally, this view of comovement predicts that there will be a common factor in the returns of securities that are held and traded by a specific subset of investors, such as individual investors.

Finally the information diffusion view suggests that new information impacts on different groups of securities at distinct speeds. The basic idea is that news is incorporated more rapidly in the most liquid stocks such as those included in a market index and rather more slowly in less liquid stocks. The causes of this may be differential access to new information or costs of trading various securities. The upshot is differential effects on comovement. For instance, the Scholes and Williams (1977) study drops the frictionless markets hypothesis by assuming lags in the incorporation of fundamentals news into some stock prices. This provides the basis for Vijh's (1994) early study of additions to the S\&P 500 stock index.

\subsection{Barberis et al. (2004) reduced form model}

This section summarizes the reduced form behavioral model outlined in Barberis et al. (2004). The economy contains a riskless asset in perfectly elastic supply with a zero rate of return and $2 n$ risky assets in fixed supply. Risky asset $i$ is a claim to a single liquidating dividend $D_{i, T}$ to be paid at $T$. The eventual dividend equals:

$$
D_{i, T}=D_{i, 0}+\varepsilon_{i, 1}+. .+\varepsilon_{i, T}
$$

where $D_{i, 0}$ is known at time 0 and $\varepsilon_{i, t}$ becomes known at time $t$, and where

$$
\varepsilon_{t}=\left(\varepsilon_{1, t}, \ldots \varepsilon_{2 n, t}\right) \prime \sim i i d N\left(0, \Sigma_{d}\right), \text { over time. }
$$

The price of a share of risky asset $i$ at time $t$ is $P_{i, t}$ and its return is

$$
\Delta P_{i, t}=P_{i, t}-P_{i, t-1}
$$

Let us suppose that some investors allocate their funds between just two categories of assets, $X$ and $Y$ rather than on an individual asset basis. Let risky assets 1 through $n$ fall into category $X$ while assets $n+1$ to $2 n$ fall into $Y$. For simplicity, let $X$ and $Y$ be index and non-index stocks, respectively, although other categorizations are possible. 
Suppose that noise traders adopt the category approach. Then asset returns can be represented as:

$$
\begin{gathered}
\Delta P_{i, t}=\varepsilon_{i, t}+\Delta u_{X, t}, \quad i \in X \\
\Delta P_{j, t}=\varepsilon_{j, t}+\Delta u_{Y, t}, \quad j \in Y \\
u_{X, t} \sim i i d N\left(\left(\begin{array}{c}
0 \\
0
\end{array}\right), \sigma_{u}^{2}\left(\begin{array}{cc}
1 & \rho_{u} \\
\rho_{u, t} & 1
\end{array}\right)\right), \text { over time. }
\end{gathered}
$$

Here $u_{X, t}$ are the time $t$ shocks or noise trader sentiment about category $X$ or index stocks. These shocks are the same across all index stocks due to the similar demand for such stocks and because these investors allocate funds at the category level. Equation (3) implies that returns and prices increase when noise traders become more bullish about stocks in $X$ as well as when good cash flow news becomes available.

Likewise, equation (3) and (4) can be the reduced form equations for the habitat view of comovement where $X$ and $Y$ now represent different habitats such as mutual funds. Here $u_{X, t}$ is a variable indicating the risk aversion, liquidity or sentiment needs of say individual traders. The mutual fund returns are thus affected by shocks to the latter's sentiment inter alios as well as by cash flows.

Finally the information diffusion view can be represented as:

$$
\begin{gathered}
\Delta P_{i, t}=\varepsilon_{i, t}, \quad i \in X \\
\Delta P_{j, t}=\mu \varepsilon_{j, t}+(1-\mu) \varepsilon_{j, t-1}, \quad j \in Y
\end{gathered}
$$

The assumption here is that the $X$ stocks incorporate new information immediately while the $Y$ stocks only incorporate a fraction $\mu$ of news immediately and $1-\mu$ the next period.

In the Barberis et al. (2004) reduced form, behavioral models, noise traders can affect patterns of comovement since fundamental traders oneperiod horizon which limits arbitrage. They thus have to consider future noise trader demand which makes them invest less aggressively. ${ }^{7}$

\footnotetext{
${ }^{7}$ See also De Long, Shleifer, Summers, Waldmann (1990) and Shleifer and Vishny (1997) for a similar idea on short horizons.
} 
Barberis et al. (2004) outline testable predictions to uncover evidence of sentiment or friction-induced comovement. One set of predictions describes what happens when a stock enters a new category like a stock market index. Many stocks are regularly added to market indexes like the S\&P 500 and FTSE 100 to replace stocks that have been removed due to downsizing, bankruptcy or merger.

Proposition 1: Suppose that risky asset $j$, previously a member of $Y$, is reclassified into $X$. Then, assuming a fixed cash-flow covariance matrix $\Sigma_{D}$, and as the number of risky assets $n \rightarrow \infty$, the probability limit of the OLS estimate of $\beta_{j}$ in the univariate regression

$$
\Delta P_{j, t}=\alpha_{j}+\beta_{j} \Delta P_{X, t}+v_{j, t}
$$

where $\Delta P_{X, t}=\Sigma \frac{1}{n} \Delta P_{i, t}$ as well as that of the $R^{2}$ of this regression, increase after reclassification.

This can be rationalized using the category view although it can readily be achieved using the other views also. When asset $j$ enters category $X$, it is affected by noise traders' flows of funds in and out of that category. This increases its covariance with the return on category $X, \Delta P_{X, t}$, and hence also its beta loading on that return. We assume for simplicity that the cash-flow covariance matrix remains fixed but this could be relaxed.

Proposition 2: Suppose that risky asset $j$, previously a member of $Y$, is reclassified into $X$ and a fixed cash-flow covariance matrix $\Sigma_{D}$. Then, as the number of risky assets grows $n \rightarrow \infty$, the probability limit of the OLS estimate of $\beta_{j, X}$ in the bivariate regression

$$
\Delta P_{j, t}=\alpha_{j}+\beta_{j, X} \Delta P_{X, t}+\beta_{j, Y} \Delta P_{Y, t}+v_{j, t}
$$

rises after reclassification, while that of the OLS estimate of $\beta_{j, Y}$ falls. ${ }^{8}$

The basic prediction is that when a stock enters category $X$, it becomes more sensitive to a category $X$ sentiment shock $u_{X, t}$. The independent variable in the univariate regression, $\Delta P_{X, t}$, is not a proper measure of this since a substantial part of its variation is due to news about cash flows. In the above regression $\Delta P_{Y, t}$ can be thought of as a control for such news, making the coefficient on $\Delta P_{X, t}$ a cleaner measure of sensitivity to $\Delta u_{X, t}$. An early version of Proposition 1 can be found in Vijh (1994) but Proposition 2 is one of the main innovations of the Barberis et al. (2004) study.

\footnotetext{
${ }^{8}$ The pre- and post-classification values of the slope coefficients also satisfy a number of restrictions.
} 
Trading-based comovement depends on the existence of noise traders who allocate funds by category, preferred habitats, or on heterogeneous rates of information diffusion. In the absence of these features, Predictions 1 and 2 will not hold and comovement will be entirely fundamentals-based. The correlation of returns will then be determined by the correlation of cash flow news. Thus both the slope coefficients and $R^{2}$ in Predictions 1 and 2 will be unchanged.

\section{Empirical Analysis}

\subsection{Data}

The data used in the empirical analysis relate to the FTSE 100 index (FTSE hereafter) which is the most popular index based on London Stock Exchange companies. The London exchange ranks second in the world behind the New York exchange both in terms of turnover and market capitalization. The FTSE 100 index was established in 1984 but we focus on the more recent 1992-2002 period. The latter coincides with a set of changes to the entry and exit procedures and an increase in the popularity of index tracking funds and related derivative products.

The organization of the FTSE 100 Index is undertaken by the FTSE Steering Committee which conducts a quarterly review of its constituent companies. Its procedures were altered in April 1992 following the introduction of futures and options contracts on LIFFE to link index changes with the expiration dates of these contracts. Since then, the review takes place in the second week of the month and any changes are implemented on the Monday after the third Friday of the month, the day on which traded derivatives contracts expire. ${ }^{9}$ As a result, there is a consistent number of trading days between the announcement and event dates over our entire sample.

In our empirical study, we analyze the returns of some 58 additions to and 61 deletions from the FTSE. Thus, while our sample size readily exceeds that of Greenwood and Sosner (2002), it is still small relative to the scale of that of Barberis et al. (2004). Nonetheless it comprehensively covers the relevant changes to the FTSE in the most recent 11-year period since the establishment of LIFFE and the introduction of new procedures for index changes.

\footnotetext{
${ }^{9}$ See Mase (2002) for more details of changes to the FTSE.
} 
Finally, note that the changes to the FTSE 100 index satisfy the three criteria outlined in Barberis et al. (2002). First, the FTSE can viewed as a natural category or as a preferred habitat for many investors. Second, there have been clear and identifiable changes in the FTSE membership since 1992. Finally, to control for fundamentals-based comovement, a stock's entry to or exit from the FTSE should not change the correlation of the stock's fundamental value with that of other FTSE stocks.

Figure 1 plots the entry and exit events over the entire sample period.

[Figure 1 around here]

Change in index membership are relatively evenly spread over the course of the sample period with the possible exception of 1994 when very few changes occurred. A large number of stocks entered and exited the index in some years such as 1992, 2000 and 2001.

\subsection{Univariate Regression Findings}

We run the following regression for each inclusion and exclusion event:

$$
R_{i t}=\alpha_{i}+\beta_{i} R_{F T S E, t}+u_{i t}
$$

where $R_{i t}$ is the return on the event stock between $t-1$ and $t, R_{F T S E, t}$ is the return on the FTSE 100 index. $^{10}$ All the return data were taken from Datastream. The weekly pre-event regression is run over the $[-52,-1]$ window before the announcement week and the post-event regression over the $[+1,+52]$ window following the implementation week. The daily regressions are estimated over the same windows. ${ }^{11}$ We test the hypothesis that the changes in $\beta_{F T S E, i}$ and in $R^{2}$ of included and excluded stocks are zero.

The focus of interest is the average (across all relevant events) change in the slope coefficient and in the coefficient of determination pre- and postevent. The mean group estimator is used for this purpose. ${ }^{12}$ Accordingly,

\footnotetext{
${ }^{10}$ The FTSE return was adjusted to reflect the inclusion or exclusion event to avoid spurious correlation effects. The implication is the $R_{F T S E, t}$ variable includes 100 stocks before an addition event and 99 thereafter. The reverse pattern holds for deletion events.

${ }^{11}$ Our sample was too short to run monthly regression over a 36 -month estimation period.

${ }^{12}$ One of the attractive properties of the MG procedure is that allows for heterogeneity in the intercepts, slope coefficients and error variances. Thus the usual high frequency GARCH effects are not an issue.
} 
parameters estimates and their associated standard errors are obtained from a two-step procedure. In the first step, the above regression - allowing for stock-specific intercepts and slope coefficients - is run separately for each security to obtain the individual slope estimates $\hat{\beta}_{i}$ and coefficients of determination.

This simple MG estimate assumes that $R_{i t}$ and $u_{i t}$ are independently distributed for all $t$ and $i$ or that the $R_{i t}$ are strictly exogenous. Typically, there are multiple deletions and additions at each quarterly review. We thus have to relax the assumption that $R_{i t}$ and $u_{i t}$ are independently distributed to take account of the important issue of cross sectional dependence stemming from simultaneous events in time. To deal with this, the seemingly unrelated regression (SUR) FGLS procedure rather than OLS is deployed in the first step. We refer to the resultant estimators as SUR-MG. In the second step, the average slope coefficients and their standard errors are calculated as follows:

$$
\begin{gathered}
\bar{\beta}=\sum_{i=1}^{N} \hat{\beta}_{i} / N \\
s e(\bar{\beta})=\sigma\left(\hat{\beta}_{i}\right) / \sqrt{N}
\end{gathered}
$$

where

$$
\sigma\left(\hat{\beta}_{i}\right)=\sqrt{\sum_{i=1}^{N}\left(\hat{\beta}_{i}-\bar{\beta}\right)^{2} /(N-1)}
$$

These standard errors provide an appropriate estimator in the presence of cross-equation correlation. ${ }^{13}$ The standards errors for the coefficients of determination are calculated analogously.

The aggregate results of the univariate regressions are presented in Table 1.

[Table 1 around here]

They indicate that stocks added to and deleted from the FTSE-100 index experience a strongly significant change in betas or slope coefficient as well as in $R^{2}$. The changes are significant both at the daily and the weekly

\footnotetext{
${ }^{13}$ Greenwood and Sosner also use the SUR procedure to deal with cross sectional dependence while Barberis et al. (2004) use simulation methods to calculate appropriate standard errors.
} 
frequencies. For instance, for the full sample the daily $\overline{\Delta \beta}_{F T S E}$ for index additions is 0.340 , while the daily $\overline{\Delta R^{2}}$ is 0.115 . The corresponding figures for the deletions from the index are -0.352 and -0.073 , respectively. Interestingly, although Barberis et al. (2004) find that the deletions from the S\&P 500 do not exhibit significant changes in $\overline{\Delta \beta}$ (excluding daily betas) and $\bar{\Delta} \bar{R}^{2}$, this does not seem to be the case for the FTSE deletions.

Both deleted and added stocks experience significant changes in comovement not only during the full estimation period but also when the latter is divided into two sub-periods. It is clear that both $\overline{\Delta \beta}$ and $\overline{\Delta R^{2}}$ are strikingly larger in magnitude for the second than for the first sub-period. This holds both for deletions and additions as well as for daily and weekly returns. For example, the increase in weekly $\overline{\Delta \beta}_{F T S E}$ is 0.162 for inclusions over the 1992-1997 period. This jumps to 0.583 for the more recent 1998-2002 period and is thus similar to the Greenwood and Sosner (2002) average beta increase of 0.55 for inclusions in the Nikkei in 2000. Our corresponding weekly $\overline{\Delta R^{2}}$ is just 0.067 in the first sub-sample but rises to 0.156 in the second. The difference in the changes between the two sub-periods is always statistically significant but more strongly so — at the 1\% level — for the 1998-2002 period.

The larger and more strongly significant changes in the second subsample, apart from being supportive of trading-induced or behavioral-based comovement of returns, indicate that the importance of the FTSE-100 index, both as a category and habitat, has risen in the recent years. Barberis et al. (2004) also find that recent US data provide stronger evidence of friction or sentiment-based comovement. Their second sub-sample spanning the 19882000 period largely overlaps with our full estimation period 1992-2002, thus confirming the increasing importance of trading-based comovement.

Comparing our results with those of Barberis et al. (2004), we note that friction- and sentiment based comovement is even more striking in the UK market than in its US counterpart. The weekly beta shifts for additions to the S\&P500 is 0.173 during the $1988-2000$ period while the corresponding beta shift in the UK market $1992-2002$ is more than double that at 0.380 . A similar pattern holds for the deletions also. Finally, while Barberis et al. (2004) found evidence that comovement decreases at lower frequencies implying an eventual reversion of noise-trader sentiment or incorporation of market-wide news into prices, no such pattern is evident from our daily and weekly results. In this respect our findings are more in accord with those of 
Greenwood and Sosner (2002) for the Nikkei.

\subsection{Bivariate Regression Findings}

One of the original contributions of Barberis et al. (2004) was to propose bivariate regressions tests of comovement. The basis for this is given in Proposition 2 that predicts that, controlling for the return of non-FTSE stocks, a stock added to (removed from) the FTSE 100 index will experience a beta increase (decrease). The following bivariate regression is run for each entry and exit event for both the period prior to and following the event:

$$
R_{i t}=\alpha_{i}+\beta_{i, F T S E} R_{F T S E, t}+\beta_{i, N F T S E} R_{N F T S E, t}+v_{i t}
$$

where $R_{F T S E, t}$ is as previously defined and $R_{N F T S E, t}$ the return on the nonFTSE stocks between period $t-1$ and $t$. The latter return is inferred from the index return and capitalization data using the identity that the return of FTSE 100 stocks and of non-FTSE 100 stocks equals the overall FTSE All Share return. For all entry and exclusion events, the hypothesis that changes in $\beta_{i, F T S E}, \beta_{i, N F T S E}$ are zero is tested.

The results of the bivariate regressions are also presented in Table 1 . The quantities reported are the average changes in the coefficients with respect to the index $\bar{\Delta}_{\bar{\beta}}^{---}$and with respect to the non-index return $\bar{\Delta}_{\text {NFTSE }}^{---}$. The changes for both inclusions and deletions are strongly significant and thus provide additional support for the behavioral theories of comovement. For instance, the weekly increase in $\beta_{i, F T S E}$ for additions is 0.603 while the decrease in $\beta_{i, N F T S E}$ for exits is -0.872 . The corresponding Barberis et al. (2004) weekly return S\&P figures of 0.202 and -0.115, respectively, for the 1988-2000 period are rather smaller. For deletions, the average decrease in daily $\beta_{i, F T S E}$ is -0.516 and the increase in $\beta_{i, N F T S E}$ is 0.922 .

The bivariate beta shifts are substantially larger and statistically more significant than their univariate counterparts. The univariate daily beta shift for inclusions rises from 0.340 to 0.508 in the bivariate regressions. The $\bar{\Delta} \beta_{F T S E}^{---}$for entrants in the first sub-period is significant at the $1 \%$ significance level in the bivariate regressions while in the univariate regressions it is significant at the $10 \%$ significance level. Again the beta shifts are substantially larger in the more recent 1998-2002 period.

Overall, our results on changes in FTSE and non-FTSE betas are consistent with the findings of previous studies of index changes which originated 
with Vijh (1994). However there appears to be a marked increase in the effect of index changes over time consistent with the growing popularity of index products within the investment community across stock exchanges. For instance, Vijh (1994) finds that a stock's daily beta with the market goes up by a statistically significant 0.08 after inclusion. ${ }^{14}$ Barberis et al. (2004) report a corresponding daily beta increase of 0.357 in their bivariate regressions over the 1988-2000 period. Finally, we find a daily beta increase of 0.363 and 0.644 for FTSE inclusions in our bivariate regressions over the 1992-1997 and 1998-2002 periods, respectively.

\subsection{Isolating the Information Diffusion Effect}

We examine whether the observed beta shifts are due to the habitat and category theories of comovement or to the slow diffusion of information into stock prices. The effect of the latter can be isolated from the other two behavioral theories of comovement by employing a prediction unique to the diffusion mechanism. Specifically, if FTSE stocks incorporate information quicker than non-FTSE stocks, then there should be positive cross-autocorrelation between FTSE and non-FTSE returns. The intuition is that news about aggregate cash flows is reflected virtually immediately in FTSE prices but only at a later date in non-FTSE prices. Positive cross-autocorrelation might also be present if market-wide sentiment and cash flow news are similarly incorporated more quickly.

We test the above prediction by following a technique proposed by Dimson (1979) and also employed by Barberis et al. (2004). The univariate and bivariate regressions are extended to include not only the contemporaneous FTSE 100 and non-FTSE returns but also five leads and five lags of each independent variable, respectively. We estimate the following regression at the daily frequency in the univariate case:

$$
R_{i t}=\alpha_{i}+\sum_{s=-5}^{5} \beta_{i}^{(s)} R_{F T S E, t+s}+u_{i t}
$$

while the bivariate regressions take the form

$$
R_{i t}=\alpha_{i}+\sum_{s=-5}^{5} \beta_{i, F T S E}^{(s)} R_{F T S E, t+s}+\sum_{s=-5}^{5} \beta_{i, N F T S E}^{(s)} R_{N F T S E, t+s}+u_{i t}
$$

\footnotetext{
${ }^{14}$ Note that Vijh (1994) estimated betas with respect to the overall market return rather than the S\&P return.
} 
These regressions are estimated for each firm $i$ before and after the inclusion (deletion) event over the same windows as previously.

The changes in the sum of the lagged, contemporaneous and leading beta coefficients $-\sum_{s=-5}^{5} \beta_{i}^{(s)}$ for the univariate and $\sum_{s=-5}^{5} \beta_{i, F T S E}^{(s)}, \sum_{s=-5}^{5} \beta_{i, N F T S E}^{(s)}$ for the bivariate regressions, respectively ${ }^{15}$ — are the beta shifts in a world without slow information diffusion effects. If these Dimson beta changes are closer to zero than the average beta shifts in Table 1, then slow information diffusion plays a role in our findings. However, if these Dimson beta shifts are still nonzero, then the habitat and category mechanisms play a role.

Panel A of Table 2 shows the shifts of the Dimson beta for inclusions and deletions for daily returns.

[Table 2 around here]

Daily rather than weekly returns are considered since market-wide cash flow news and sentiment would be expected to be incorporated into prices within a matter of days rather than weeks. The comparison between beta shifts in Table 1 and Dimson beta shifts suggests a role for slow incorporation of news into prices. Both the univariate and bivariate shifts in Dimson betas are generally closer to zero than their counterparts in Table 1. The univariate beta shifts for entry events are significant in both sub-periods but those for exits are insignificant over the full period.

The bivariate beta shifts remain statistically significant for entries in all periods and exits for the full sample period. This provides support for the category and habitat theories of comovement. The bivariate regressions suggest that information diffusion accounts for about one quarter of the inclusion and one fifth of the deletion beta shifts in Table 1. This compares favorably with Barberis et al. (2004) who find that information diffusion accounts for one third of the shifts in their S\&P sample.

Another way of demonstrating that information diffusion plays a role is by examining how the components of Dimson betas vary following changes in index constituency. In Panel B of Table 2, each column represents changes in lagged, contemporaneous and leading beta estimates $\left(\Delta \beta_{i}^{(s)}, \Delta \beta_{i, F T S E}^{(s)}\right.$ and $\left.\Delta \beta_{i, N F T S E}^{(s)}\right)$ while each row refers to a particular point in time $(t$ for contem-

\footnotetext{
${ }^{15}$ Strictly speakung, these betas should be weighted. However since Barberis et al. (2004) find that the weights are all close to 1, we use unweighted betas.
} 
poraneous and $t-s$ with $-5 \leq s<0$ and $0<s \leq 5$ for lagged and leading betas respectively).

In particular, a fall in the loading of the previous day's FTSE 100 return, $\Delta \beta_{i}^{(-1)}$, is consistent with slow incorporation of market-wide news into prices. ${ }^{16}$ The fall suggests that market-wide news is reflected in the stock price with a one day lag before inclusion while news is reflected on the same day after inclusion. The delay in incorporating news is relatively short since only the previous three days' beta loadings are significant in the univariate regressions while they are not really significant in the bivariate regressions. A similar intuition holds for the significant changes in the following day FTSE and non-FTSE loadings, suggesting a role for information diffusion again.

In summary, although slow information diffusion does play a role, it explains about one quarter of the shifts in bivariate regressions where the previous days' betas are also insignificant. The corollary is that the category and habitat mechanisms account for most of the beta shifts in these regressions. The relatively small information diffusion effect is also consistent with the absence of a frequency effect in our results.

\section{Robustness Checks}

In this section we consider alternative explanations for comovement that might be responsible for the changes in the beta coefficients. More specifically we report the results of two robustness checks on the findings reported in Table 1. In general, alternative explanations may be relevant when the inclusion of stocks in the FTSE 100 index coincides with a change in the covariance matrix even if it does not cause it. In other words, FTSE 100 stocks as well as those stocks chosen for inclusion might share a common characteristic. If the latter is also associated with a cash-flow or discount rate factor, this rather than trading-based comovement may explain our results.

\subsection{Size and Industry Effects}

Size is a really important characteristic in our study since the FTSE 100 Index comprises of the 100 largest capitalization stocks in the UK market. It is thus possible that the beta shifts reported above may be explained by the

\footnotetext{
${ }^{16}$ Note that the loading on $\left.\Delta \beta_{i, F T S E}^{(-1)}\right)$ is insignificant in the bivariate regression.
} 
fact that market capitalization or size are associated with a cash-flow factor. The findings of Fama and French (1995) suggest a common component to news about the earnings of large-cap stocks. One alternative explanation of the beta changes might therefore be that stocks grow in size around inclusion and, once included, increase the loading on the large stock cash-flow factor.

Industry is another potentially relevant factor. When one industry becomes more dominant in the economy the following two effects are likely to be observed. Firstly the FTSE Committee will probably choose stocks for inclusion mainly from that particular industry in order to make their index as representative of the UK economy as possible. Secondly, the growing importance of the industry will be reflected in the value-weighted return of the FTSE 100, since the fraction of the value of the index comprised of the specific industry's stocks will increase. As a result we might observe excessive correlation of returns which will be due to industry specific news and its artificially increased influence on the index return.

Following the Barberis at al. (2004) methodology, a matching stock is sought for each event stock. This matching stock should be in the same industry and should exhibit the same growth in market capitalization as the event stock during the 52-week, pre-event estimation period. For inclusion event stocks, the matching stock should have remained outside the index and vice versa for deletion events. With the above characteristics, the matching stock should theoretically be as good a candidate for inclusion (deletion) as the event stock which actually was added to (deleted from) the index. If the beta change of matching stocks is less than that for the event stocks, this provides evidence in favour of the sentiment- and friction-based theories of comovement.

At the daily and weekly frequencies we search for a matching stock that matches the event stock on size both at the beginning and the end of the preevent estimation period of 52 weeks. We seek a match first at the Datastream industry classification level 6 and within one size decile both at the beginning and at the end of the pre-event estimation period. If no such match is found, we search for a match in the Datastream industry classification level 4, within one size decile both at inclusion and one year previously. ${ }^{17}$ If a match cannot be found, we look for a match at classification level 3 and within two size deciles both at inclusion and one year before. Finally we allow for a three size decile search at level 3 classification. If a stock has more than one match

\footnotetext{
${ }^{17}$ Level 5 and level 6 classifications are the same for the UK.
} 
at level 3, the selected match is that which has a similar classification at level 6 or level 4 to the event stock. We also make sure that the matching stock has not been chosen as a match for another event which has an overlapping pre-estimation period as the initial event stock. Event stocks for which no such matches can be found are excluded.

The results of the matching exercise are shown in Table 3.

[Table 3 around here]

The coefficients examined are changes net of changes for the analogous matching stocks. For the univariate regressions we examine the net changes in beta $(\Delta \Delta \beta)$ and coefficient of determination $\left(\Delta \Delta R^{2}\right)$, while for the bivariate regressions we examine the net changes in the FTSE 100 beta and the non-FTSE 100 beta. If the matching stocks exhibit similar behavior to the event stocks, then the net changes should be statistically insignificant. Panel A contains the results for daily returns while panel $\mathrm{B}$ contains the results for the weekly returns. Both the univariate and the bivariate net changes for the full sample period (1992-2002) remain strongly significant in the two panels. In particular, the net daily return changes remain significant at the $1 \%$ level except for entries 1992-1997 where the univariate change is insignificant and the bivariate $\Delta \Delta \beta_{F T S E}$ significance level drops to $10 \%$. For weekly returns, the net changes for entries remain significant at the same confidence levels while those for exits remain virtually the same. These findings demonstrate that size and industry factors cannot explain our earlier results. Instead they vindicate behavioral theories of comovement.

Interestingly, our results do not seem to support one of the predictions of the behavioral theories of Barberis at al. (2004) that the beta shifts decline at lower frequencies. We find the average daily beta shift for entries is 0.414 while the weekly beta shift is rather larger at 0.575 . The daily beta changes over the full sample are mainly significant at the $1 \%$ level while the weekly beta shifts remain significant mainly at the $1 \%$ level for the full sample period. They are insignificant only in a few cases for the sub-periods.

\subsection{Asynchronous Trading}

It has long been known that asynchronous or non-trading causes positive autocorrelations in index returns based on the last observed prices of individual stocks. Scholes and Williams (1977) and Dimson (1979) show that 
non-synchronous trading and the use of high frequency (daily) data bias the estimated betas. Their hypothesis states that index trading strategies increase the trading frequency of index stocks and related derivative products. As a result, index stock prices reflect market information more immediately and thus accurately whereas non-index stock prices are often dated since they reflect news only with a lag. Their model predicts that the betas of stocks added to an index will increase as their trading frequencies move closer to the market average but not in other cases. By contrast the price pressure hypothesis or trading view predicts that betas will increase in every case.

Thus we examine the proposition that the changes in beta coefficients are driven by non-trading. Stocks outside the index are usually less frequently traded than stocks already in the index. This is plausible given the fact that equities in the index attract the attention of index funds and institutional investors.

To illustrate this, suppose that some positive market wide information is released toward the end of a particular trading day. Since FTSE 100 stocks are heavily traded, they are more likely to reflect the news since they probably will be traded again on that day. Consequently the return of the index should reflect the new information on the day the information becomes available. On the other hand, one would expect non- index stocks not to reflect the news immediately since it is unlikely that they will traded again that day.

Therefore, in a regression of $R_{i, t}$ on $R_{F T S E, t}$, where stock $i$ is outside the index, the coefficient estimate will be mechanically lower. By contrast, if stock $i$ is added to the index, the absence of asynchronous trading effects will result in a rise of the beta coefficient. The non-trading hypothesis thus suggests that the beta increases for added stocks can be explained by more frequent trading post-entry. Since asynchronous trading leads to similar results as comovement, it is worthwhile investigating whether our results are driven by non-trading.

We employ a test suggested by Vijh (1994). The sample of included stocks is divided into two groups, one whose post-addition turnover (share volume divided by shares outstanding) decreases and another whose turnover increases. The average monthly turnover over the beta estimation period is computed to allocate stocks into the two groups. A stock is assigned to the first group if its post-event average turnover is less than its pre-event average turnover and to the second group otherwise.

Under the assumption that our results are driven by asynchronous trading, only the increasing turnover group should exhibit a beta increase. As- 
suming trading-induced comovement effects, both groups should exhibit a rise in beta coefficients. The results are presented in Table 4. Panel A contains the averaged beta and $R^{2}$ changes for the shares with a post-event turnover decrease and panel $\mathrm{B}$ the corresponding results for shares exhibiting a post-event increase.

\section{[Table 4 around here]}

Both the univariate and bivariate changes in betas and $R^{2}$, respectively, are significant in both groups, mainly at the $1 \%$ significance level. This indicates that asynchronous trading is not driving our results. If the latter plays some role, then the univariate changes in Panel B should be larger than those in Panel A. We find the opposite for the full sample period and 1998-2002 where the univariate changes in betas are larger for the Panel A than the panel B group.

Non-sychronous trading could also explain some of our results if the ratio of the absolute increase in FTSE beta $\beta_{i, F T S E}$ to absolute decrease in nonFTSE beta $\beta_{i, N F T S E}$ is larger for panel B. However, a comparison between these ratios indicates that they are rather similar for both panels. Thus asynchronous trading does not play a major role in the Table 1 results.

Overall, we can conclude that our results are largely robust both to size and to asynchronous trading effects. The lack of impact of stocks matched by size and industry is particularly important for our sample since the FTSE is constructed to include the 100 largest stocks by market capitalization.

\section{Conclusions}

In this paper, we empirically test two competing approaches to return comovement using a sample of stock index changes from the London Stock Exchange. One is the traditional model that attributes comovement to correlation in news about fundamental value. The other consists of the behavioral models outlined in Barberis et al. (2004) that explain comovement by correlated investor demand shifts for securities in a given category, by demand shifts by specific investor clienteles or by slow diffusion of information.

Specifically these approaches are tested by investigating the impact of additions to and deletions from the FTSE 100 index for the 1992-2002 period. These changes are interesting since they alter a stock's category and habitat but have no ostensible impact on its fundamentals. We find that, when 
stocks are added to the index, their beta coefficients and R-squared with respect to the index increase significantly post entry. Stocks deleted from the index display the opposite pattern post exit. In bivariate regressions the beta coefficients of FTSE entrants display more substantial increases while simultaneously their betas with respect to non-index stocks fall sharply. The results are more pronounced for the more recent 1998-2002 sub-period underlining the growing importance of index funds in the UK. We find that slow information diffusion accounted for only a quarter of the overall changes and that neither industry (size) effects nor non-synchronous trading had a significant effect on our findings.

Our findings support those of Barberis et al. (2004) for the S\&P 500 index and of Greenwood and Sosner (2002) for the Nikkei index in providing evidence for the category and habitat and views of comovement. They reveal that index changes lead to relatively substantial changes in comovement in the UK. Our results add to the growing body of evidence underlining the importance of behavioral factors in explaining changes in financial economics. 


\section{References}

[1] Barberis, N., Shleifer, A., (2003) Style investing, Journal of Financial Economics 68, 161-199.

[2] Barberis, N., Shleifer, A., Vishny, R., (1998) A model of investor sentiment, Journal of Financial Economics 49, 307-343.

[3] Barberis, N., Shleifer, A., Wurgler, J., (2002) Comovement, Harvard Institute of Economic Research Discussion Paper Number 1953.

[4] Barberis, N., Shleifer, A., Wurgler, J., (2004) Comovement, Journal of Financial Economics, Forthcoming.

[5] Campbell, J. Y., Lo, A.W., MacKinlay, C., (1997) The Econometrics of Financial Markets, Princeton University Press, Princeton, NJ.

[6] Chen, H., Noronha, G., Singal, V., (2004) The price response to S\&P 500 index additions and deletions: Evidence of asymmetry and a new explanation, Journal of Finance, Forthcoming.

[7] Commerzbank (2001) Sharks versus shark bait: Trading in response to the MSCI changes, London.

[8] Daniel, K., Hirshleifer, D., Subrahmanyam, A., (1998) Investor psychology and security market under- and overreactions, Journal of Finance $53,1839-1885$.

[9] De Long, J.B., Shleifer A., Summers L., Waldmann, R., (1990) Noise trader risk in financial markets, Journal of Political Economy 98, 703-38.

[10] Denis, D.K, McConnell, J.J., Ovtchinnikov, A., Yu, Y., (2003) S\&P 500 Index additions and earnings expectations, Journal of Finance 58, 1821-1840.

[11] Dimson, E., (1979) Risk measurement when shares are subject to infrequent trading, Journal of Financial Economics 7, 197-227

[12] Fama, E., French. K, (1995) Size and book-to-market factors in earnings and returns, Journal of Finance 50, 131-155. 
[13] Greenwood, R.M., (2001) Large events and limited arbitrage: Evidence from a Japanese stock index definition, Discussion Paper, Harvard University.

[14] Greenwood, R.M., Sosner, N., (2002) Where do betas come from? Discussion Paper, Harvard University.

[15] Harris, L.E., (1989) S\&P 500 cash stock price volatilities, Journal of Finance 44, 1155-1176.

[16] Harris, L., Gurel, E., (1986) Price and volume effects associated with changes in the S\&P 500: New evidence for the existence of price pressure, Journal of Finance 41, 851-860.

[17] Hong, H., Stein, J.C., (1999) A unified theory of underreaction, momentum trading, and overreaction in asset markets, Journal of Finance 54, 2143-2184.

[18] Kaul, A., Mehrotra V., Morck, R., (2000) Demand curves for stocks do slope down: New evidence from an index weights adjustment. Journal of Finance 55, 893-912.

[19] Lee, C., Shleifer A., Thaler, R., (1991) Investor sentiment and the closedend fund puzzle, Journal of Finance 46, 75-110.

[20] Lynch, A., Mendenhall, R., (1997). New evidence on stock price effects associated with changes in the S\&P 500 Index, Journal of Business 70, $351-83$.

[21] Mase, B., (2002) The impact of changes in the FTSE 100 index, Brunel Department of Economics and Finance Discussion Paper 02-25.

[22] Scholes, M. S., Williams J.T., (1977) Estimating betas from nonsynchronous data, Journal of Financial Economics 5, 309-327.

[23] Shleifer, A., (1986) Do demand curves for stocks slope down? Journal of Finance 41, 579-590.

[24] Shleifer A., Vishny, R., (1997) The limits of arbitrage, Journal of Finance 52, 35-55. 
[25] Vijh, A.M., (1994) S\&P trading strategies and stock betas, Review of Financial Studies 7, 215-251.

[26] Wurgler, J., Zhuravskaya, K., (2002) Does arbitrage flatten demand curves for stocks? Journal of Business 75, 583-608. 


\section{Table 1. Changes in comovement of stocks added to and deleted from the FTSE 100.}

Changes in the slope and fit of regressions of returns of stocks added to and deleted from the FTSE 100 index on returns of the FTSE 100 Index and the non-FTSE 100 rest of the market. The sample includes stocks added to and deleted from the FTSE 100 between 1992 and 2000 that were not involved in mergers or related events and that have sufficient return data on Datastream. For each added or deleted stock $j$, the univariate model

$$
R_{j, t}=\alpha_{j}+\beta_{j} R_{F T S E, t}+v_{j, t}
$$

and the bivariate model

$$
R_{j, t}=\alpha_{j}+\beta_{j, F T S E} R_{F T S E, t}+\beta_{j, N F T S E} R_{N F T S E, t}+v_{j, t}
$$

are separately estimated from the pre-change and post-change period. Returns on the FTSE $100\left(R_{F T S E}\right)$ are from Datastream. Returns on the capitalization-weighted index on the non-FTSE 100 stocks $\left(R_{N F T S E}\right)$ are inferred from the identity

$$
R_{A L L, t}=\left(\frac{C A P_{A L L, t-1}-C A P_{F T S E, t-1}}{C A P_{A L L, t-1}}\right) R_{N F T S E, t}+\left(\frac{C A P_{F T S E, t-1}}{C A P_{A L L, t-1}}\right) R_{F T S E, t}
$$

where $R_{A L L, t}$ and $C A P_{A L L, t}$ are the FTSE All Share return and capitalization respectively. The mechanical influence of the added or deleted stock is removed from the independent variables as appropriate. For the univariate regression model, we examine the mean difference between the pre-change slope and the post-change slope $\bar{\Delta} \beta$, and the mean change in fit $\bar{\Delta} \bar{R}$. For the bivariate model, we examine the mean changes in the slopes, $\bar{\Delta} \beta_{F T S E}$ and $\bar{\Delta} \beta_{N F T S E}$. The pre-change and post-estimation periods are $[-52,-1]$ and $[+1,+52]$ weeks for daily and weekly returns. Panels A and B show results for daily and weekly returns, respectively. Standards errors from the SUR procedure to account for cross-correlation are reported in parentheses. ${ }^{* * *},{ }^{* *}$, and ${ }^{*}$ denote statistical significance at the $1 \%, 5 \%$ and $10 \%$ levels in one-sided tests, respectively. 


\begin{tabular}{|c|c|c|c|c|c|c|}
\hline & & \multicolumn{3}{|c|}{ Univariate } & \multicolumn{2}{|l|}{ Bivariate } \\
\hline & Sample & $\mathrm{N}$ & $\begin{array}{l}\bar{\Delta} \bar{\beta} \\
(s . e)\end{array}$ & $\begin{array}{c}\Delta R^{-} \bar{R}^{2} \\
(s . e)\end{array}$ & $\begin{array}{c}\bar{\Delta} \bar{\beta}_{F T S E}^{---} \\
(888)\end{array}$ & 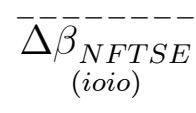 \\
\hline & & & \multicolumn{3}{|c|}{ Panel A.Daily Returns } & \\
\hline \multirow[t]{3}{*}{ Entries } & $1992-2002$ & 58 & $\begin{array}{l}0.340^{* * *} \\
(0.061)\end{array}$ & $\begin{array}{l}0.115^{* * *} \\
(0.021)\end{array}$ & $\begin{array}{l}0.508^{* * *} \\
(0.052)\end{array}$ & $\begin{array}{c}-0.812^{* * *} \\
(0.211)\end{array}$ \\
\hline & $1992-1997$ & 28 & $\begin{array}{l}0.096^{*} \\
(0.069)\end{array}$ & $\begin{array}{l}0.049^{* *} \\
(0.021)\end{array}$ & $\begin{array}{l}0.363^{* * *} \\
(0.068)\end{array}$ & $\begin{array}{c}-0.970^{* * *} \\
(0.253)\end{array}$ \\
\hline & $1998-2002$ & 30 & $\begin{array}{l}0.567^{* * *} \\
(0.080)\end{array}$ & $\begin{array}{l}0.175^{* * *} \\
(0.033)\end{array}$ & $\begin{array}{l}0.644^{* * *} \\
(0.071)\end{array}$ & $\begin{array}{c}-0.664^{* *} \\
(0.333)\end{array}$ \\
\hline \multirow[t]{3}{*}{ Exits } & $1992-2002$ & 61 & $\begin{array}{c}-0.352^{* * *} \\
(0.050)\end{array}$ & $\begin{array}{c}-0.073^{* * *} \\
(0.011)\end{array}$ & $\begin{array}{c}-0.516^{* * *} \\
(0.065)\end{array}$ & $\begin{array}{l}0.922^{* * *} \\
(0.251)\end{array}$ \\
\hline & $1992-1997$ & 35 & $\begin{array}{c}-0.214^{* * *} \\
(0.043)\end{array}$ & $\begin{array}{c}-0.053^{* * *} \\
(0.013)\end{array}$ & $\begin{array}{c}-0.389^{* * *} \\
(0.078)\end{array}$ & $\begin{array}{l}0.984^{* * *} \\
(0.311)\end{array}$ \\
\hline & $1998-2002$ & 26 & $\begin{array}{c}-0.539^{* * *} \\
(0.093)\end{array}$ & $\begin{array}{c}-0.099^{* * *} \\
(0.018)\end{array}$ & $\begin{array}{c}-0.687^{* * *} \\
(0.101)\end{array}$ & $\begin{array}{l}0.838^{* *} \\
(0.422)\end{array}$ \\
\hline
\end{tabular}

Panel B. Weekly Returns

\begin{tabular}{|c|c|c|c|c|c|c|}
\hline \multirow[t]{3}{*}{ Entries } & $1992-2002$ & 58 & $\begin{array}{l}0.380^{* * *} \\
(0.090)\end{array}$ & $\begin{array}{l}0.113^{* * *} \\
(0.025)\end{array}$ & $\begin{array}{l}0.603^{* * *} \\
(0.104)\end{array}$ & $\begin{array}{c}-0.872^{* * *} \\
(0.312)\end{array}$ \\
\hline & $1992-1997$ & 28 & $\begin{array}{l}0.162^{*} \\
(0.112)\end{array}$ & $\begin{array}{l}0.067^{* *} \\
(0.035)\end{array}$ & $\begin{array}{l}0.456^{\text {*** }} \\
(0.126)\end{array}$ & $\begin{array}{c}-0.850^{* * *} \\
(0.351)\end{array}$ \\
\hline & $1998-2002$ & 30 & $\begin{array}{l}0.583^{* * *} \\
(0.131)\end{array}$ & $\begin{array}{l}0.156^{* * *} \\
(0.033)\end{array}$ & $\begin{array}{l}0.740^{* * *} \\
(0.162)\end{array}$ & $\begin{array}{c}-0.892^{* *} \\
(0.514)\end{array}$ \\
\hline \multirow[t]{3}{*}{ Exits } & $1994-2002$ & 61 & $\begin{array}{c}-0.474^{* * *} \\
(0.103)\end{array}$ & $\begin{array}{l}-0.073^{* * *} \\
(0.019)\end{array}$ & $\begin{array}{c}-0.587^{* * *} \\
(0.131)\end{array}$ & $\begin{array}{l}0.760^{* *} \\
(0.389)\end{array}$ \\
\hline & $1994-1998$ & 35 & $\begin{array}{c}-0.252^{* *} \\
(0.104)\end{array}$ & $\begin{array}{c}-0.074^{* * *} \\
(0.027)\end{array}$ & $\begin{array}{c}-0.486^{* * *} \\
(0.142)\end{array}$ & $\begin{array}{l}0.987^{* * *} \\
(0.390)\end{array}$ \\
\hline & $1999-2002$ & 26 & $\begin{array}{c}-0.772^{* * *} \\
(0.184)\end{array}$ & $\begin{array}{c}-0.073^{* * *} \\
(0.027)\end{array}$ & $\begin{array}{c}-0.724^{* * *} \\
(0.243)\end{array}$ & $\begin{array}{l}0.455 \\
(0.753)\end{array}$ \\
\hline
\end{tabular}


Table 2. Changes in comovement of stocks added to and deleted from the FTSE 100 Index : Information diffusion effects (5 leads and 5 lags).

Changes in the slope and the fit of regressions of daily returns on stocks added to and deleted from the FTSE 100 Index on daily returns of the FTSE 100 Index and the nonFTSE 100 rest of the market, using five leads and lags in daily returns to adjust beta for information diffusion effects as suggested by Dimson (1979). The sample includes stocks added to and deleted from the FTSE 100 between 1992 and 2002 that were not involved in mergers or related events and that have sufficient return data on Datastream. For each added stock $j$, the univariate model

$$
R_{j, t}=\alpha_{j}+\sum_{s=-5}^{5} \beta_{j}^{(s)} R_{F T S E, t}+v_{j, t}
$$

and the bivariate model

$$
R_{j, t}=\alpha_{j}+\sum_{s=-5}^{5}\left(\beta_{j}^{(s)} R_{F T S E, t}+\beta_{j, N F T S E}^{(s)} R_{N F T S E, t}\right)+v_{j, t}
$$

are separately estimated for the pre-change and post-change period. In Panel A, we report the mean difference between the pre-change and post-change components of the Dimson beta (which is defined as the sum of the lag, contemporaneous and lead coefficients). In Panel B, we report the mean difference between pre-change and post-change components of the Dimson beta. Standards errors from the SUR procedure to account for crosscorrelation are reported in parentheses. ${ }^{* * *},{ }^{* *}$, and ${ }^{*}$ denote statistical significance at the $1 \%, 5 \%$ and $10 \%$ levels in one-sided tests, respectively.

$$
\text { Sample } \quad N \quad \begin{gathered}
\text { Univariate } \\
\bar{\Delta} \bar{\beta}
\end{gathered} \quad \begin{gathered}
\bar{\Delta}(s . e) \\
R^{2}
\end{gathered}
$$

\begin{tabular}{|c|c|c|c|c|c|c|}
\hline \multirow[t]{3}{*}{ Entries } & $1992-2002$ & 58 & $\begin{array}{l}0.028 \\
(0.111)\end{array}$ & $\begin{array}{l}0.107^{* * *} \\
(0.022)\end{array}$ & $\begin{array}{l}0.383^{* * *} \\
(0.147)\end{array}$ & $\begin{array}{c}-0.991^{* * *} \\
(0.329)\end{array}$ \\
\hline & $1992-1997$ & 28 & $\begin{array}{c}-0.237^{* *} \\
(0.096)\end{array}$ & $\begin{array}{l}0.052^{* *} \\
(0.024)\end{array}$ & $\begin{array}{l}0.261^{*} \\
(0.171)\end{array}$ & $\begin{array}{c}-0.884^{* *} \\
(0.394)\end{array}$ \\
\hline & 1998-2002 & 30 & $\begin{array}{l}0.274^{*} \\
(0.186)\end{array}$ & $\begin{array}{l}0.160^{* * *} \\
(0.034)\end{array}$ & $\begin{array}{l}0.498^{* *} \\
(0.236)\end{array}$ & $\begin{array}{c}-1.090^{* *} \\
(0.525)\end{array}$ \\
\hline Exits & 1992-2002 & 61 & $\begin{array}{c}-0.161 \\
(0.125)\end{array}$ & $\begin{array}{c}-0.067^{* * *} \\
(0.012)\end{array}$ & $\begin{array}{c}-0.429^{*} \\
(0.258)\end{array}$ & $\begin{array}{l}0.928^{* *} \\
(0.548)\end{array}$ \\
\hline
\end{tabular}

Panel A. Dimson Beta (5 leads and lags) 
Panel B. Components of Dimson Beta (5 leads and 5 lags)

\begin{tabular}{|c|c|c|c|c|c|}
\hline \multirow{12}{*}{ Entries } & \multirow{12}{*}{ 1992-2002 } & & Univariate & \multicolumn{2}{|l|}{ Bivariate } \\
\hline & & $t-5$ & $\begin{array}{c}-0.045^{* *} \\
(0.024)\end{array}$ & $\begin{array}{l}\text { FTSE } \\
-0.029 \\
(0.031)\end{array}$ & $\begin{array}{l}\text { Non-FTSE } \\
0.092 \\
(0.143)\end{array}$ \\
\hline & & $t-4$ & $\begin{array}{c}-0.024 \\
(0.024)\end{array}$ & $\begin{array}{l}0.029 \\
(0.038)\end{array}$ & $\begin{array}{c}-0.130 \\
(0.151)\end{array}$ \\
\hline & & $t-3$ & $\begin{array}{c}-0.063^{* * *} \\
(0.024)\end{array}$ & $\begin{array}{l}0.061^{*} \\
(0.039)\end{array}$ & $\begin{array}{c}-0.408^{* * *} \\
(0.158)\end{array}$ \\
\hline & & $t-2$ & $\begin{array}{c}-0.035^{* * *} \\
(0.021)\end{array}$ & $\begin{array}{l}0.043 \\
(0.033)\end{array}$ & $\begin{array}{c}-0.400^{* *} \\
(0.169)\end{array}$ \\
\hline & & $t-1$ & $\begin{array}{c}-0.070^{* * *} \\
(0.027)\end{array}$ & $\begin{array}{c}-0.052 \\
(0.045)\end{array}$ & $\begin{array}{l}0.025 \\
(0.213)\end{array}$ \\
\hline & & $t$ & $\begin{array}{l}0.344^{* * *} \\
(0.062)\end{array}$ & $\begin{array}{l}0.466^{* * *} \\
(0.053)\end{array}$ & $\begin{array}{c}-0.731^{* * *} \\
(0.213)\end{array}$ \\
\hline & & $t+1$ & $\begin{array}{l}0.019 \\
(0.024)\end{array}$ & $\begin{array}{l}-0.113^{* * *} \\
(0.035)\end{array}$ & $\begin{array}{l}0.664^{* * *} \\
(0.158)\end{array}$ \\
\hline & & $t+2$ & $\begin{array}{c}-0.017 \\
(0.027)\end{array}$ & $\begin{array}{c}-0.015 \\
(0.041)\end{array}$ & $\begin{array}{l}0.034 \\
(0.153)\end{array}$ \\
\hline & & $t+3$ & $\begin{array}{c}-0.004 \\
(0.032)\end{array}$ & $\begin{array}{l}0.014 \\
(0.034)\end{array}$ & $\begin{array}{l}0.038 \\
(0.123)\end{array}$ \\
\hline & & $t+4$ & $\begin{array}{c}-0.027^{* * *} \\
(0.021)\end{array}$ & $\begin{array}{l}0.022 \\
(0.033)\end{array}$ & $\begin{array}{c}-0.236^{*} \\
(0.153)\end{array}$ \\
\hline & & $t+5$ & $\begin{array}{c}-0.051^{* *} \\
(0.026)\end{array}$ & $\begin{array}{c}-0.043 \\
(0.041)\end{array}$ & $\begin{array}{l}0.061 \\
(0.158)\end{array}$ \\
\hline
\end{tabular}


Table 3. Changes in comovement of stocks added to and deleted from the FTSE 100 Index : Relative to matching firms.

Changes in the slope and the fit of regressions of returns of stocks added to and deleted from the FTSE 100 Index relative to changes in the same parameters of matching stocks. Each stock in the event sample is paired with another stock that matches it on industry and growth in market capitalization over the pre-change estimation period (described in text). The event sample includes stocks added to and deleted from the FTSE 100 between 1992 and 2002 that were not involved in mergers or related events (described in text), which have sufficient return data on Datastream and for which a matching stock could be found. For each added or deleted stock $j$, the univariate model

$$
R_{j, t}=\alpha_{j}+\beta_{j} R_{F T S E, t}+v_{j, t}
$$

and the bivariate model

$$
R_{j, t}=\alpha_{j}+\beta_{j, F T S E} R_{F T S E, t}+\beta_{j, N F T S E} R_{N F T S E, t}+v_{j, t}
$$

are separately estimated from the pre-change and post-change periods and analogous regressions are run for each matching stock. Returns on the FTSE 100 are from Datastream. For the univariate regression model, we examine the mean difference between the pre-change and post-change slope and fit of the event stock and the matching stock, $\bar{\Delta} \bar{\Delta} \bar{\beta}$ and $\bar{\Delta} \bar{\Delta} R^{2}$. For the bivariate model we examine the mean difference between the changes in the slopes of the event stock and the matching stock, $\bar{\Delta} \bar{\Delta} \bar{\beta}_{F T S E}^{---}$and $\bar{\Delta} \bar{\Delta} \bar{\beta}_{N F T S E}^{-----}$ The pre-change and post-change estimation periods are $[-52,-1]$ and $[+1,+52]$ weeks for daily and weekly returns. Standards errors from the SUR procedure to account for crosscorrelation are reported in parentheses. ${ }^{* * *},{ }^{* *}$, and ${ }^{*}$ denote statistical significance at the $1 \%, 5 \%$ and $10 \%$ levels in one-sided tests, respectively. 


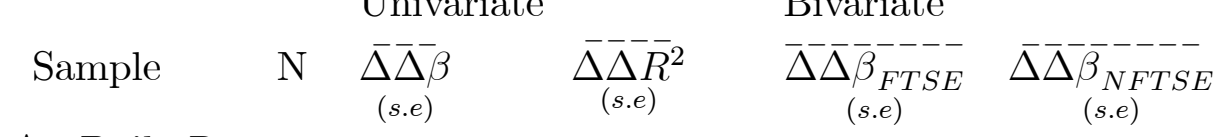

Panel A. Daily Returns

\begin{tabular}{|c|c|c|c|c|c|c|}
\hline \multirow[t]{3}{*}{ Additions } & $1992-2002$ & 43 & $\begin{array}{l}0.180^{* * *} \\
(0.072)\end{array}$ & $\begin{array}{l}0.108^{* * *} \\
(0.025)\end{array}$ & $\begin{array}{l}0.414^{* * *} \\
(0.097)\end{array}$ & $\begin{array}{l}-1.108^{* * *} \\
(0.335)\end{array}$ \\
\hline & $1992-1997$ & 19 & $\begin{array}{l}0.046 \\
(0.114)\end{array}$ & $\begin{array}{l}0.045^{* *} \\
(0.025)\end{array}$ & $\begin{array}{l}0.226^{*} \\
(0.166)\end{array}$ & $\begin{array}{c}-0.525 \\
(0.544)\end{array}$ \\
\hline & $1998-2002$ & 24 & $\begin{array}{l}0.286^{* * *} \\
(0.089)\end{array}$ & $\begin{array}{l}0.158^{* * *} \\
(0.037)\end{array}$ & $\begin{array}{l}0.562^{* * *} \\
(0.108)\end{array}$ & $\begin{array}{l}-1.570^{* * *} \\
(0.403)\end{array}$ \\
\hline \multirow[t]{3}{*}{ Deletions } & $1992-2002$ & 40 & $\begin{array}{c}-0.264^{* * *} \\
(0.053)\end{array}$ & $\begin{array}{c}-0.080^{* * *} \\
(0.023)\end{array}$ & $\begin{array}{c}-0.413^{* * *} \\
(0.081)\end{array}$ & $\begin{array}{l}0.874^{* * *} \\
(0.351)\end{array}$ \\
\hline & $1992-1997$ & 23 & $\begin{array}{l}-0.211^{* * * *} \\
(0.038)\end{array}$ & $\begin{array}{c}-0.036^{* *} \\
(0.020)\end{array}$ & $\begin{array}{l}-0.358^{* * *} \\
(0.102)\end{array}$ & $\begin{array}{l}0.765^{*} \\
(0.465)\end{array}$ \\
\hline & $1998-2002$ & 17 & $\begin{array}{c}-0.337^{* * *} \\
(0.112)\end{array}$ & $\begin{array}{c}-0.139^{* * *} \\
(0.044)\end{array}$ & $\begin{array}{c}-0.488^{* * *} \\
(0.134)\end{array}$ & $\begin{array}{l}1.022^{* *} \\
(0.550)\end{array}$ \\
\hline \multicolumn{7}{|c|}{ Panel B. Weekly Returns } \\
\hline \multirow[t]{3}{*}{ Additions } & $1992-2002$ & 43 & $\begin{array}{l}0.215^{* *} \\
(0.097)\end{array}$ & $\begin{array}{l}0.090^{* * *} \\
(0.027)\end{array}$ & $\begin{array}{l}0.575^{* * *} \\
(0.143)\end{array}$ & $\frac{-1.344^{* * *}}{(0.434)}$ \\
\hline & $1992-1997$ & 19 & $\begin{array}{l}0.164 \\
(0.141)\end{array}$ & $\begin{array}{l}0.058 \\
(0.045)\end{array}$ & $\begin{array}{l}0.355^{*} \\
(0.227)\end{array}$ & $\begin{array}{c}-0.608 \\
(0.575)\end{array}$ \\
\hline & $1998-2002$ & 24 & $\begin{array}{l}0.256^{* *} \\
(0.135)\end{array}$ & $\begin{array}{l}0.116^{* * *} \\
(0.032)\end{array}$ & $\begin{array}{l}0.750^{* * *} \\
(0.179)\end{array}$ & ${ }_{(0.614)}^{-1.927^{* * *}}$ \\
\hline \multirow[t]{3}{*}{ Deletions } & $1992-2002$ & 40 & $\begin{array}{l}-0.289^{* * *} \\
(0.109)\end{array}$ & $\begin{array}{l}-0.077^{* * *} \\
(0.031)\end{array}$ & $\begin{array}{l}-0.495^{* * *} \\
(0.177)\end{array}$ & $\underset{(0.536)}{1.061^{* *}}$ \\
\hline & $1992-1997$ & 23 & $\begin{array}{l}-0.204^{*} \\
(0.120)\end{array}$ & $\begin{array}{l}-0.058^{* *} \\
(0.033)\end{array}$ & $\begin{array}{l}-0.571^{* * *} \\
(0.214)\end{array}$ & $\begin{array}{l}1.403^{* * * *} \\
(0.554)\end{array}$ \\
\hline & $1998-2002$ & 17 & $\begin{array}{l}-0.404^{* *} \\
(0.200)\end{array}$ & ${ }^{-0.103^{* *}}$ & $\begin{array}{c}-0.393 \\
(0.306)\end{array}$ & $\begin{array}{l}0.598 \\
(1.025)\end{array}$ \\
\hline
\end{tabular}


Table 4. Changes in comovement of stocks added to and deleted from the FTSE 100 : By change in trading volume.

Changes in the slope and fit of regressions of returns of stocks added to the FTSE 100 index on returns of the FTSE 100 Index and the non-FTSE 100 rest of the market. The sample includes stocks added to the FTSE 100 between 1992 and 2002 that were not involved in mergers or related events and that have sufficient return data on Datastream. For each added or deleted stock $j$, the univariate model

$$
R_{j, t}=\alpha_{j}+\beta_{j} R_{F T S E, t}+v_{j, t}
$$

and the bivariate model

$$
R_{j, t}=\alpha_{j}+\beta_{j, F T S E} R_{F T S E, t}+\beta_{j, N F T S E} R_{N F T S E, t}+v_{j, t}
$$

are separately estimated for the pre-change and post-change periods of $[-52,-1]$ and $[+1,+52]$ weeks of daily data. Average pre-change and post-change turnover (volume divided by shares outstanding) are computed over these same intervals and used to identify the direction in trading volume. Panel A reports results for stocks that decreased turnover while Panel B reports results for stocks that increased turnover. Standards errors from the SUR procedure to account for cross-correlation are reported in parentheses. ${ }^{* * *},{ }^{* *}$, and ${ }^{*}$ denote statistical significance at the $1 \%, 5 \%$ and $10 \%$ levels in one-sided tests, respectively.

\begin{tabular}{|c|c|c|c|c|c|c|}
\hline \multicolumn{2}{|l|}{ Sample } & $\mathrm{N}$ & $\begin{array}{l}\bar{\Delta} \bar{\beta} \\
(s . e)\end{array}$ & $\underset{(s . e)}{\Delta R^{2}}$ & $\begin{array}{c}\Delta \bar{\beta}_{F T S E} \\
(s . e)\end{array}$ & $\begin{array}{c}\Delta \beta_{N F T S E} \\
(s . e)\end{array}$ \\
\hline & & \multicolumn{3}{|c|}{ Panel A. } & \multicolumn{2}{|c|}{ Turnover decrease } \\
\hline \multirow[t]{3}{*}{ Additions } & 1992-2002 & 20 & $\begin{array}{l}0.413^{* * *} \\
(0.116)\end{array}$ & $\begin{array}{l}0.085^{* * *} \\
(0.023)\end{array}$ & $\begin{array}{l}0.590^{* * *} \\
(0.111)\end{array}$ & $\begin{array}{c}-0.931^{* * *} \\
(0.365)\end{array}$ \\
\hline & $1992-1997$ & 12 & $\begin{array}{l}0.100 \\
(0.097)\end{array}$ & $\begin{array}{l}0.037^{*} \\
(0.026)\end{array}$ & $\begin{array}{l}0.340^{* * *} \\
(0.117)\end{array}$ & $\begin{array}{c}-0.842^{* *} \\
(0.441)\end{array}$ \\
\hline & $1998-2002$ & 8 & $\begin{array}{l}0.884^{* * *} \\
(0.129)\end{array}$ & $\begin{array}{l}0.156^{* * *} \\
(0.026)\end{array}$ & $\begin{array}{l}0.966^{* * *} \\
(0.134)\end{array}$ & $\begin{array}{c}-1.063^{*} \\
(0.665)\end{array}$ \\
\hline & & \multicolumn{3}{|c|}{ Panel B } & \multicolumn{2}{|c|}{ Turnover increase } \\
\hline \multirow[t]{3}{*}{ Additions } & $1992-2002$ & 35 & $\begin{array}{l}0.344^{* * *} \\
(0.072)\end{array}$ & $\begin{array}{l}0.143^{* * *} \\
(0.032)\end{array}$ & $\begin{array}{l}0.501^{* * *} \\
(0.054)\end{array}$ & $\begin{array}{c}-0.722^{* * *} \\
(0.282)\end{array}$ \\
\hline & 1992-1997 & 14 & $\begin{array}{l}0.141 \\
(0.106)\end{array}$ & $\begin{array}{l}0.068^{* *} \\
(0.036)\end{array}$ & $\begin{array}{l}0.432^{* * *} \\
(0.088)\end{array}$ & $\begin{array}{c}-1.073^{* * *} \\
(0.350)\end{array}$ \\
\hline & 1998-2002 & 21 & $\begin{array}{l}0.479^{* * *} \\
(0.088)\end{array}$ & $\begin{array}{l}0.192^{* * *} \\
(0.045)\end{array}$ & $\begin{array}{l}0.547^{* * *} \\
(0.069)\end{array}$ & $\begin{array}{c}-0.488 \\
(0.408)\end{array}$ \\
\hline
\end{tabular}

Univariate Bivariate 
Figure 1. Changes to the FTSE 100 Index $1992-2002$

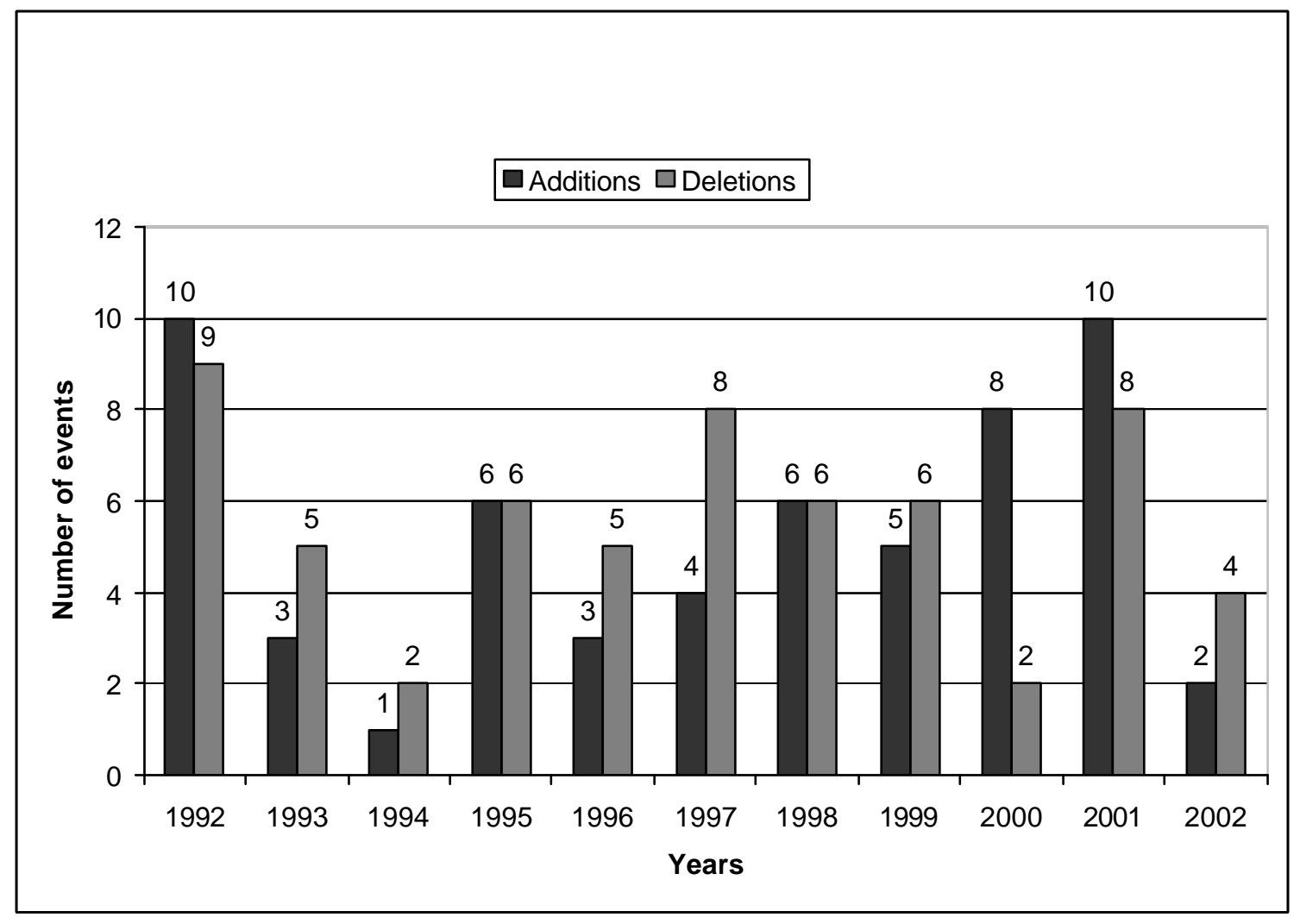

From April 1992 to June 2002, a total of 181 constituent changes to the FTSE 100 index took place. Our sample includes only 58 inclusion stocks and 61 deletion stocks. This is because inclusion events are excluded if the new firm is a spin off or a new version of a firm already in the index, if the firm is engaged in a merger or takeover around the inclusion event, or if the required data are not available. Deletion events are excluded if the firm is involved in a merger, takeover, or bankruptcy proceeding, or if the required data are not available. The annual notes of the FTSE Actuaries share indices for the UK were used in the above event categorization. We also exclude events in which companies remain in or outside the index for a period less than 52 weeks either after the implementation day, or before the announcement day, or both. Return data were obtained by Datastream. 